\title{
PENERAPAN TEXT NETWORK ANALYSIS DALAM MENGANALISIS PENDAPAT CUSTOMER PRODUCT PATRIOT DI SHOPEE
}

\author{
Ignatius Adrian Mastan ${ }^{1 *}$, Yohanes Wendy ${ }^{2}$ \\ ${ }^{1,2}$ Program Studi Sistem Informasi, Fakultas Teknologi dan Desain \\ Universitas Bunda Mulia \\ Jalan Lodan Raya No. 2 Ancol, Jakarta Utara 14430 \\ *Corresponding Author: imastan@bundamulia.ac.id
}

\begin{abstract}
E-commerce has changed the buying and selling process and the way people interact via the internet. One company that uses e-commerce is PT Patriot Memory Indonesia. PT Patriot Memory Indonesia sells well-known computer peripherals, including the Solid State Drive (SSD). PT Patriot Memory Indonesia wants to analyze customer feedback regarding SSD products sold in e-commerce, namely Shopee by using Text Network Analysis (TNA) which is one part of social computing. Social computing is a science that focuses on social behavior and social contexts using computing systems. One of the tools of social computing, namely Text Network Analysis (TNA), is a research technique that focuses on identifying and comparing network relationships between words, sentences, and systems to model interactions that generate new knowledge or information. In this study, Text Network Analysis will show consumer perceptions through the feedback it provides on buyer reviews. The opinions expressed by consumers in buyer reviews can be analyzed so that they can connect each word and create associations of consumer perceptions of a product. Thus, it can be seen the aspects that must be addressed by the company to improve consumer perceptions. The problem analyzed is the development of social computing in analyzing big data. Can the company take advantage of this information so that they know the perceptions of their consumers through the information in the customer feedback at Shopee. Through Text Network Analysis in social computing, researchers will know the association of each word of consumer perception and can see the perception that has the highest degree of a product and see its relationship with other perceptions. This study looks at consumer perceptions of Patriot SSD products at Shopee. The results of this study can help provide customer feedback information to PT Patriot Memory Indonesia.
\end{abstract}

Keywords: text network analysis, customer feedback, Shopee.

\section{ABSTRAK}

E-commerce telah banyak mengubah proses jual beli dan cara berinteraksi dengan melalui internet. Salah satu perusahaan yang menggunakan $e$-commerce adalah PT Patriot Memory Indonesia. PT Patriot Memory Indonesia menjual peripheral 
computer yang sangat terkenal, antara lain adalah Solid State Drive (SSD). PT Patriot Memory Indonesia ingin menganalisis customer feedback mengenai produk SSD yang dijual di e-commerce yaitu Shopee dengan menggunakan Text Network Analysis (TNA) yang merupakan salah satu bagian dalam social computing. Social computing merupakan ilmu yang berfokus tentang perilaku sosial dan konteks sosial menggunakan sistem komputasi. Salah satu tool dari social computing yaitu Text Network Analysis (TNA), yaitu teknik penelitian yang berfokus pada identifikasi dan membandingkan hubungan jaringan antara kata, kalimat, dan sistem untuk model interaksi yang menghasilkan pengetahuan atau informasi yang baru. Dalam penelitian ini, Text Network Analysis akan menunjukkan persepsi konsumen melalui feedback yang diberikannya pada ulasan pembeli. Pendapat yang dilontarkan konsumen di ulasan pembeli dapat dianalisis sehingga dapat menghubungkan tiap kata dan memunculkan asosiasi persepsi konsumen terhadap suatu produk. Dengan demikian, dapat dilihat aspek yang harus dibenahi oleh perusahaan untuk membenahi persepsi konsumen. Masalah yang dianalisis adalah pengembangan social computing dalam menganalisis big data. Apakah perusahaan dapat memanfaatkan informasi tersebut sehingga mengetahui persepsi konsumennya melalui informasi di customer feedback di Shopee. Melaui Text Network Analysis dalam social computing, peneliti akan mengetahui asosiasi tiap kata persepsi konsumen dan bisa melihat persepsi yang memiliki derajat tertinggi terhadap suatu produk dan melihat keterkaitannya dengan persepsi yang lain. Penelitian ini melihat persepsi konsumen terhadap produk SSD Patriot di Shopee. Hasil penelitian ini dapat membantu memberikan informasi customer feedback kepada PT Patriot Memory Indonesia.

Kata kunci: analisis jaringan teks, umpan balik pelanggan, Shopee.

\section{PENDAHULUAN}

Saat ini dengan semakin pesatnya perkembangan teknologi dan internet di Indonesia, memberikan dampak yang sangat besar terhadap perubahan pola bisnis. Perubahan terjadi mulai dari cara beriklan, cara jual beli, cara berinteraksi antar manusia, dan sebagainya. Contoh e-commerce di Indonesia yang sudah populer dan memiliki reputasi yang baik adalah seperti Tokopedia, Shopee, Bukalapak, Lazada dan lain sebagainya. E-commerce adalah sebuah layanan internet yang dimanfaatkan untuk jual beli. E-commerce telah banyak mengubah proses transaksi jual beli. Jika pada transaksi jual beli konvensional, penjual dan pembeli bertemu langsung, maka pada transaksi jual beli dengan e-commerce penjual dan pembeli tidak perlu bertemu langsung. Penjual dan pembeli berinteraksi dengan melalui internet maupun dengan komunikasi melalui telepon. Dalam proses ini, kepercayaanlah yang menjadi modal utama. Karena tanpa saling percaya di antara kedua belah pihak, maka proses jual beli e-commerce tidak bisa terjadi atau tidak dapat terlaksana. Dengan perkembangan yang semakin pesat, maka banyak toko onlinele-commerce bermunculan, dengan memanfaatkan blog, social media, atau 
website. Perkembangan ini membuat suatu transaksi jual beli menjadi semakin mudah.

Social computing merupakan ilmu yang berfokus tentang perilaku sosial dan konteks sosial menggunakan sistem komputasi. Salah satu tool dari social computing adalah Text Network Analysis (TNA) yaitu teknik penelitian yang berfokus pada identifikasi dan membandingkan hubungan jaringan antara kata, kalimat, dan sistem untuk model interaksi yang menghasilkan pengetahuan atau informasi yang baru. Dalam penelitian ini, Text Network Analysis akan menunjukkan persepsi konsumen melalui feedback yang diberikannya pada ulasan pembeli. Dalam bisnis, yang diinginkan adalah terciptanya suatu persepsi konsumen yang baik. Persepsi konsumen adalah proses di mana seseorang mengorganisir dan mengartikan kesan dari panca indera dalam tujuan untuk memberi arti dalam lingkungan mereka. Pendapat yang dilontarkan konsumen di ulasan pembeli dapat dianalisis sehingga dapat menghubungkan tiap kata dan memunculkan asosiasi persepsi konsumen terhadap suatu produk. Dari hal ini akan dapat dilihat aspek yang harus dibenahi oleh perusahaan untuk membenahi persepsi konsumen. Masalah yang akan dianalisis adalah pengembangan social computing dalam menganalisis big data. Apakah perusahaan dapat memanfaatkan informasi tersebut sehingga mengetahui persepsi konsumennya melalui informasi di media sosial. Melalui Text Network Analysis dalam social computing, peneliti akan mengetahui asosiasi tiap kata persepsi konsumen dan bisa melihat persepsi yang memiliki derajat tertinggi terhadap suatu produk dan melihat keterkaitannya dengan persepsi yang lain. Pada penelitian ini akan dilihat persepsi konsumen terhadap produk SSD Patriot di Shopee.

\section{TINJAUAN PUSTAKA \\ E-Commerce}

Menurut Kotler and Armstrong (2012), e-commerce adalah saluran online yang dapat dijangkau seseorang melalui komputer, yang digunakan oleh pebisnis dalam melakukan aktivitas bisnisnya dan digunakan konsumen untuk mendapatkan informasi dengan menggunakan bantuan komputer yang dalam prosesnya diawali dengan memberi jasa informasi pada konsumen dalam penentuan pilihan. $E$ commerce adalah proses jual beli dan memasarkan produk berupa barang atau jasa melalui sistem elektronik (Wong, 2010).

E-commerce merupakan satu set dinamis teknologi, aplikasi, dan proses bisnis yang menghubungkan perusahaan, konsumen, dan komunitas tertentu melalui transaksi elektronik dan perdagangan barang, pelayanan, dan informasi yang dilakukan secara elektronik (Baum, 1999). Menurut Laudon and Laudon (1998), e-commerce adalah suatu proses membeli dan menjual produk-produk secara elektronik oleh konsumen dan dari perusahaan ke perusahaan dengan komputer sebagai perantara transaksi bisnis. Kalakota and Whinston (1997) menyatakan e-commerce dapat ditinjau dalam 3 perspektif berikut:

1. Dari perspektif komunikasi, e-commerce adalah pengiriman barang, layanan, informasi, atau pembayaran melalui jaringan komputer atau melalui peralatan elektronik lainnya. 
2. Dari perspektif proses bisnis, e-commerce adalah aplikasi dari teknologi yang menuju otomatisasi dari transaksi bisnis dan aliran kerja.

3. Dari perspektif layanan, e-commerce merupakan suatu alat yang memenuhi keinginan perusahaan, konsumen, dan manajemen untuk memangkas biaya layanan (service cost) ketika meningkatkan kualitas barang dan meningkatkan kecepatan layanan pengiriman.

4. Dari perspektif online, e-commerce menyediakan kemampuan untuk membeli dan menjual barang ataupun informasi melalui internet dan sarana online lainnya.

\section{Big Data}

Big data adalah kemampuan untuk mengelola banyak data yang berbeda, dengan kecepatan yang tepat, dan dalam kerangka waktu yang tepat untuk memungkinkan analisis real time dan membuat data menjadi informasi sebagai dasar untuk tindakan selanjutnya (Hurwitz, 2013). Big data adalah data yang melebihi kapasitas pengolahan sistem database konvensional, data yang terlalu besar, perpindahan data yang terlalu cepat, atau tidak sesuai dengan struktur database. Menurut Provost (2013), big data memiliki tiga karakteristik utama atau biasa disebut dengan $3 \mathrm{~V}$ yaitu:

a. Volume

Nama big data sendiri memiliki arti data dengan ukuran yang besar, karena itu ukuran dari data itu sendiri memiliki peranan penting. Sebuah data dapat dikategorikan sebagai big data atau bukan tergantung dari volume data. Karena alasan tersebut, volume adalah salah satu aspek yang harus dipertimbangkan dalam menangani big data.

b. Velocity

Velocity sendiri mengacu pada kecepatan data, seberapa cepat data dapat dihasilkan, diproses, dan dianalisis untuk memenuhi suatu kebutuhan. Selain pengumpulan datanya yang harus cepat, kecepatan transfer data juga sangat berpengaruh, terlebih lagi dalam proses pengiriman data. Jika big data memiliki kecepatan yang memungkinkan, maka data dapat diterima atau digunakan secara langsung (real time).

c. Variety

Variety di sini dapat diartikan sebagai beragamnya jenis data yang dimiliki oleh big data. Biasanya tipe data tradisional lebih terstruktur, akan tetapi seiring berkembangnya big data, banyak data baru dengan bentuk data yang unstructured (tidak terstruktur) dan semi structured (semi terstruktur), seperti contohnya sebuah text atau data yang berupa audio dan video. Data-data tersebut memerlukan proses tambahan agar arti dari data dapat diketahui.

\section{User Generated Content}

User Generated Content (UGC) adalah konten yang dihasilkan dari user (Dumbill, 2012). User Generated Content adalah segala bentuk konten atau isi dalam sebuah media di dunia teknologi yang ada pada saat ini seperti blog, wiki, forum diskusi, chatting, tweet, podcasting, pin, gambar digital, video, file hingga berbagai bentuk konten media lainnya yang terbentuk melalui buatan dari para 
pengguna sistem atau layanan online. Karena User Generated Content telah berkembang, sehingga partisipasi konsumen menjadi hal yang penting sebagai marketing intelligence untuk perusahaan dengan mengolah menggunakan metode dan teknik yang tepat terhadap User Generated Content (Moens, 2014).

\section{Social Computing}

Social computing adalah sebuah ilmu yang mempelajari mengenai perilaku sosial dan konteks sosial menggunakan computational system (Liu, 2009). Social computing merupakan salah satu metode pengolahan data User Generated Content. Social computing juga merujuk kepada aplikasi digital yang dapat memudahkan interaksi dan kolaborasi di mana pengguna juga dapat berpartisipasi menjadi pembuat konten, bukan hanya sebagai pengguna akhir. Dengan adanya aplikasi semacam ini, para pengguna seperti pelanggan, pelajar, penduduk, atau para pegawai dari sebuah perusahaan memiliki peranan penting pembentukan citra suatu produk atau jasa.

Menurut Turban (2018), social computing mengacu pada sistem komputasi yang melibatkan interaksi dan perilaku sosial. Hal ini menggunakan penggunaan beberapa platform yaitu blog, wiki, layanan jejaring sosial, alat perangkat lunak sosial lainnya, dan pasar sosial. Sementara sistem komputasi tradisional berkonsentrasi pada proses bisnis, khususnya pemrosesan transaksi dan peningkatan produktivitas. Social computing berkonsentrasi pada peningkatan kolaborasi dan interaksi di antara orang-orang dan pada konten yang dibuat pengguna. Dalam social computing, e-commerce dengan menggunakan internet, dapat menemukan barang dan jasa yang direkomendasikan oleh orang lain yang memiliki relasi dengan konsumen tersebut.

\section{Text Network Analysis}

Menurut Rinaldi et al. (2018), Text Network Analysis adalah analisis text yang merupakan bagian dari social computing yang memungkinkan analisis terkait hubungan antar kata sehingga membentuk pola yang memiliki arti. Metode yang digunakan untuk menganalisis hubungan keterkaitan antar kata yaitu menggunakan Text Network Analysis. Text Network Analysis merupakan suatu jaringan yang menggambarkan keterkaitan satu kata dengan kata lainnya dilengkapi dengan tingkat keterkaitannya. Dalam jaringan terdapat 2 hal yaitu Node dan Edge yang penjelasannya adalah sebagai berikut:

1. Node merupakan titik (lingkaran) yang diterjemahkan sebagai kata yang sering muncul dan akan dicari keterkaitannya.

2. Edge merupakan garis yang menghubungkan antar Node, semakin tebal garis maka semakin erat pula tingkat keterkaitannya.

\section{METODE PENELITIAN}

Prosedur penelitian yang digunakan secara berurutan adalah Crawling Data, Data Preprocessing, Association Data, Data Modelling, dan Analyze, dapat digambarkan dengan langkah-langkah seperti terlihat pada Gambar 1. 


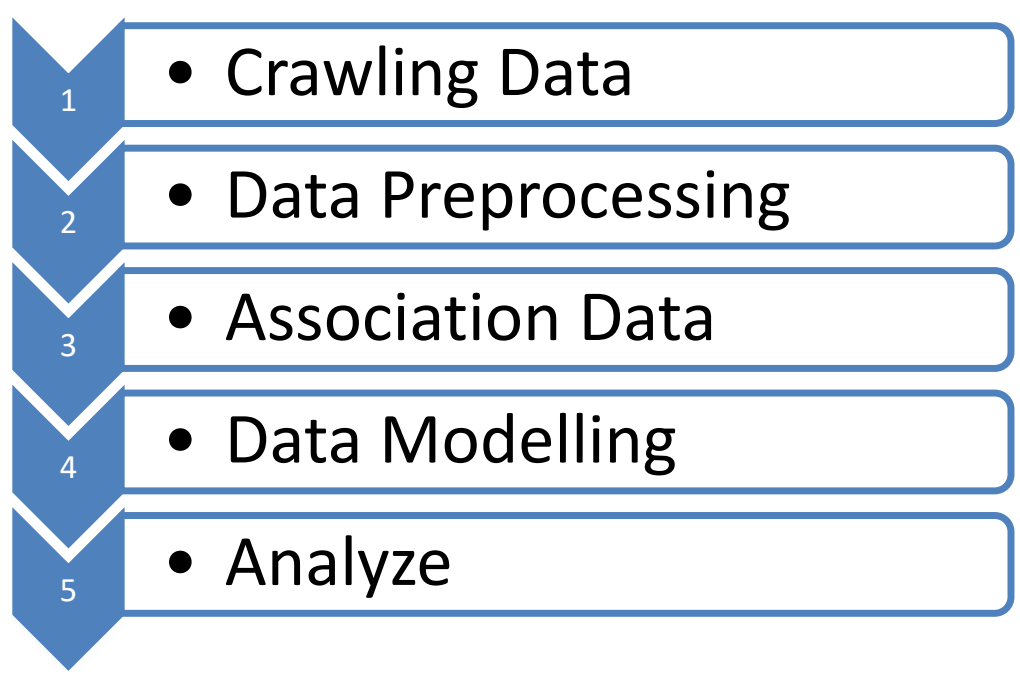

\section{Gambar 1 \\ Prosedur Penelitian}

Prosedur penelitian dapat dijabarkan sebagai berikut:

1. Tahap pertama adalah crawling data menggunakan metode Text Network Analysis dan digunakan pada website Netlytics.org dengan mengekstrak informasi pada customer feedback produk Patriot di e-commerce Shopee. Informasi diperoleh melalui crawling data di customer feedback produk Patriot di Shopee. Penggalian informasi dilakukan di customer feedback karena bersifat terbuka sehingga mempermudah crawling data. Crawling data digunakan untuk memperoleh mengenai informasi, opini, pengalaman konsumen terkait bisnis $e$ commerce Shopee dan produk Patriot. Komentar yang melambangkan persepsi dari konsumen di customer feedback tersebut selanjutnya akan diproses pada tahap data preprocessing untuk membagi setiap kata dalam sebuah komentar.

2. Pada tahap kedua, yaitu data preprocessing melalui 3 tahap: tokenization, filtering stopwords, dan stemming. Melalui tahap tokenization dilakukan proses pemecahan kalimat/relasi menjadi kata-kata dan hubungan sehingga memudahkan analisis asosiasi jaringan. Langkah selanjutnya adalah filtering stopwords yang digunakan untuk membersihkan data dari frasa atau kata-kata yang tidak berguna. Tahap akhir dari data preprocessing adalah stemming yaitu proses pembersihan imbuhan yaitu prefiks, sufiks, infiks, dan konfiks untuk menggabungkan kata yang berasal dari kata dasar dan interaksi yang sama untuk analisis asosiasi tahap berikutnya. Kata yang sudah disaring dan melewati tahap data preprocessing menjadi kumpulan kata-kata besar melalui word cloud generator serta inisialisasi jaringan. Dengan demikian, data kualitatif diperoleh pada layanan e-commerce melalui data preprocessing agar menjadi data yang berkualitas baik sebelum masuk ke dalam proses asosiasi. Hasil dari word cloud generator adalah kata dominan yang melambangkan persepsi dominan konsumen yang akan dilakukan pengolahan asosiasi kata tidak hanya memetakan kata, namun juga memetakan jaringan dari setiap hubungan sehingga terjadinya interaksi antar user dengan objek penelitian. 
3. Pada tahap ketiga, data dan jaringan diasosiasi. Tiap kata akan dihubungkan dengan kata lain dan jaringan lain yang muncul dalam satu komentar. Kemudian tahap pemodelan dengan menggunakan aplikasi yaitu Gephi dan analisis dengan modularitas untuk melihat asosiasi kata yang terbentuk.

4. Pada tahap keempat, memodelkan data pada asosiasi persepsi konsumen dibutuhkan untuk melihat bagaimana persepsi bisnis e-commerce melalui jaringan yang ada sehingga perusahaan dapat menjawab bagaimana layanan mereka di benak konsumen. Pada jaringan interaksi akan didapat hasil akhir berupa hubungan setiap interaksi yang membentuk kluster melalui customer feedback konsumen pada Shopee dan menunjukkan asosiasi persepsi konsumen terhadap layanan yang diberikan oleh $e$-commerce. Asosiasi persepsi konsumen merupakan kumpulan komentar yang disampaikan oleh konsumen di customer feedback yang ada di Shopee yang berkaitan dengan persepsi mereka.

5. Pada tahap kelima, adalah analyze di mana pada setiap interaksi yang dibangun konsumen memiliki karakteristik masing-masing yang dapat dibagi menjadi beberapa kelompok berdasarkan kesamaan. Hasil dari asosiasi persepsi konsumen adalah ringkasan dari komentar dan jaringan konsumen terkait yang dapat digunakan sebagai strategi perusahaan untuk meningkatkan retensi pelanggan dan brand image.

\section{HASIL PENELITIAN DAN PEMBAHASAN Teknik Pemodelan}

Teknik pemodelan dengan menggunakan aplikasi yaitu Gephi dan analisis dengan modularitas untuk melihat asosiasi kata yang terbentuk. Memodelkan data pada asosiasi persepsi konsumen dibutuhkan untuk melihat bagaimana persepsi bisnis e-commerce melalui jaringan yang ada sehingga perusahaan dapat menjawab bagaimana layanan mereka di benak konsumen. Pada jaringan interaksi akan didapat hasil akhir berupa hubungan setiap interaksi yang membentuk kluster melalui customer feedback konsumen pada customer feedback dan menunjukkan asosiasi persepsi konsumen terhadap layanan yang diberikan oleh e-commerce. Asosiasi persepsi konsumen merupakan kumpulan komentar yang disampaikan oleh konsumen di media sosial yang berkaitan dengan persepsi mereka.

\section{Hasil Crawling Data}

Crawling data dilakukan di dalam ulasan produk SSD Patriot di Shopee selama penjualan berlangsung, dengan menggunakan aplikasi pemograman $\mathrm{R}$ Studio. Hasilnya seperti terlihat pada Tabel 1

Tabel 1

Hasil Crawling Data

\begin{tabular}{|c|c|}
\hline Nama E-commerce & Hasil Crawling Ulasan \\
\hline Shopee & 351 Ulasan \\
\hline
\end{tabular}

Pada Tabel 1 bisa dilihat bahwa ulasan yang telah di-crawling terhadap interaksi user di aplikasi Shopee sebanyak 351 ulasan. 


\section{Persepsi Dominan Mengenai Produk SSD Patriot}

Setelah melewati data preprocessing, maka kata-kata yang diutarakan user di ulasan mengenai persepsi mereka terkait produk SSD Patriot dilakukan dengan menggunakan word cloud sehingga menghasilkan 20 kata dominan yang mewakili persepsi dari user mengenai SSD Patriot ini. Proses word cloud merupakan proses pencarian kata-kata yang dikategorikan paling penting sesuai dengan konteks penelitian ini. Beberapa kata penting yang muncul adalah Patriot, SSD, USA, Mantul, Garansi, Promo, Rapi, Packing, Favorite, Diproses, Respon, Jual, Cepat, Cek, Senang, Original, Lengkap, Berkualitas, Harga, Admin, Rusak, dan Bisa. Kata-kata penting mengenai persepsi produk SSD Patriot yang sering muncul tersebut dapat dilihat pada Gambar 2.

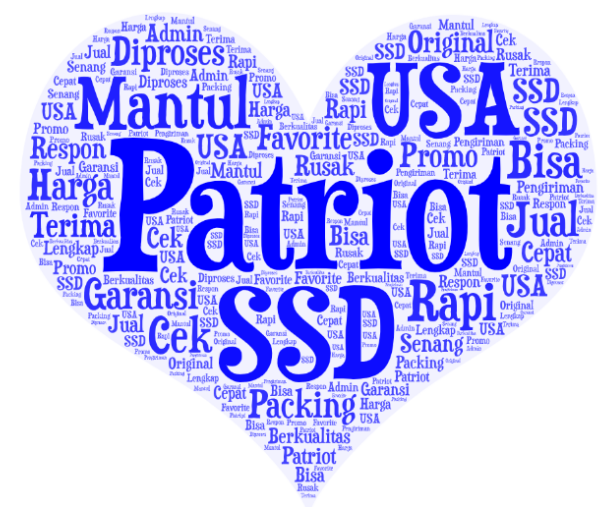

Gambar 2

\section{Persepsi Produk SSD Patriot}

Dari Gambar 2 di atas bisa kita lihat bahwa terdapat kata-kata dominan yang melambangkan persepsi user mengenai SSD Patriot. Semakin besar ukuran kata menandakan semakin tinggi entitas kemunculan kata yang melambangkan persepsi dari user.

Tabel 2

Jumlah Kemunculan Kata

\begin{tabular}{|c|c|c|c|}
\hline Kata & Entitas Kemunculan & Kata & Entitas Kemunculan \\
\hline Patriot & 156 & Garansi & 55 \\
\hline SSD & 132 & Original & 50 \\
\hline USA & 121 & Harga & 50 \\
\hline Mantul & 112 & Bisa & 50 \\
\hline Rapi & 98 & Jual & 50 \\
\hline Diproses & 87 & Cek & 50 \\
\hline Promo & 67 & Berkualitas & 50 \\
\hline Diterima & 67 & Baik & 50 \\
\hline Senang & 56 & Lengkap & 50 \\
\hline Respon & 55 & Rusak & 2 \\
\hline
\end{tabular}


Setelah mendapatkan kata apa saja yang menjadi persepsi dari user, selanjutnya penulis mencari hubungan antar kata dari hasil word cloud tersebut menggunakan metode association rules.

\section{Asosiasi Persepsi Mengenai SSD Patriot}

Berdasarkan persepsi dominan yang telah ditemukan dengan word cloud, maka dilakukan asosiasi persepsi untuk melihat hubungan antar kata yang terbentuk. Dengan menggunakan word cloud generator diperoleh kata dominan yang melambangkan persepsi dominan konsumen SSD Patriot yang akan dilakukan pengolahan asosiasi kata. Dalam hal ini tidak hanya memetakan kata, namun juga memetakan jaringan dari setiap hubungan sehingga terjadinya interaksi antar user dengan objek penelitian. Analisis asosiasi persepsi dilakukan dengan menggunakan metode Text Network Analysis (TNA) untuk membuat hubungan antar kata dengan menjadikan kata-kata sebagai Nodes dan hubungan antar kata sebagai Edges dalam hubungan. Hasil analisis asosiasi persepsi dapat ditunjukkan pada Gambar 3.

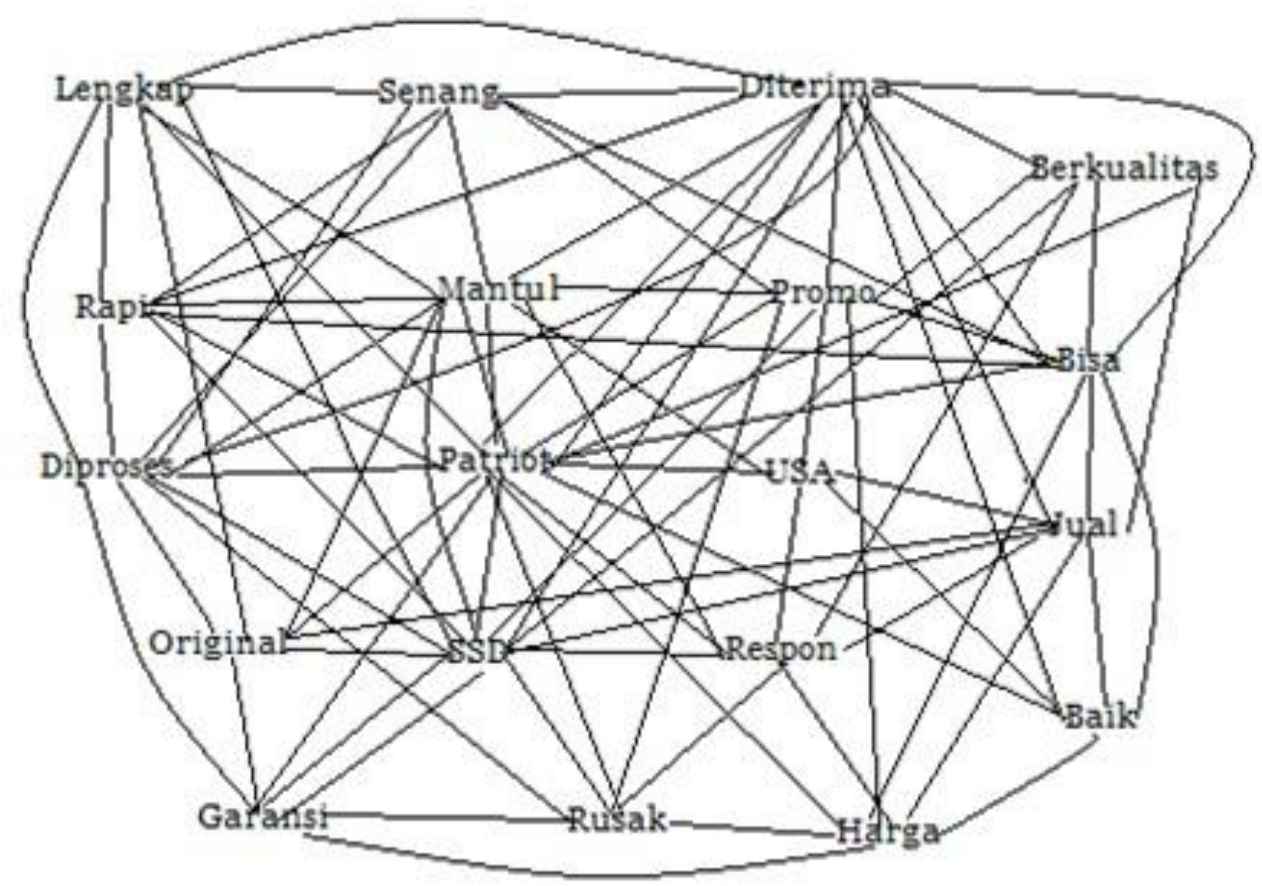

Gambar 3

Asosiasi Persepsi Mengenai SSD Patriot

Pada Gambar 3 bisa dilihat asosiasi persepsi yang terbentuk. Dapat dilihat kalau semua kata saling berhubungan dan didominasi kata-kata positif sebesar $95 \%$ dan negatif sebanyak 5\%. Analisis yang dilakukan pada setiap interaksi yang dibangun konsumen memiliki karakteristik masing-masing yang dapat dibagi menjadi beberapa kelompok persepsi berdasarkan kesamaan arti positif atau negatif. Hasil dari asosiasi persepsi konsumen adalah ringkasan dari komentar konsumen terkait yang dapat digunakan sebagai strategi perusahaan untuk meningkatkan retensi pelanggan dan brand image. Brand image membantu perusahaan dalam 
meningkatkan performa dan kepercayaan konsumen terhadap brand. Sedangkan retensi pelanggan akan membantu meningkatkan loyalitas konsumen terhadap brand atau produk yang dijual oleh perusahaan.

\section{SIMPULAN}

Melalui Text Network Analysis (TNA), peneliti dapat memodelkan persepsi user dengan baik melalui crawling data di Shopee. Pada analisis menggunakan word cloud dapat dikatakan kata dominan yang memengaruhi persepsi user terhadap produk SSD Patriot. Dari Text Network Analysis (TNA) dapat dilihat asosiasi persepsi dari user tersebut membentuk kluster berdasarkan hubungan antar kata sehingga dapat dilihat asosiasi persepsi positif dan negatif dari hasil data crawling di Shopee.

Asosiasi persepsi yang dibentuk oleh produk SSD Patriot menciptakan asosiasi persepsi positif yang dominan sehingga hal ini menandakan bahwa pelayanan dari produk SSD Patriot ini sudah baik. Hal ini terlihat pula dari kata yang dominan yaitu "Patriot", "SSD", "USA", "Mantul", "Rapi", yang menandakan user senang berbelanja Produk Patriot ini karena "Original" dan "Baik". Selain itu juga ada persepsi negatif yang perlu diperbaiki mengenai "Rusak" dan lain-lain.

Kelebihan analisis menggunakan Text Network Analysis (TNA) dibanding metode lainnya untuk melihat persepsi dari konsumen seperti Multi Dimensional Scaling (MDS) adalah biaya yang dibutuhkan lebih rendah, lebih real time dan juga mencakup area yang lebih luas karena menggunakan data yang di-crawling dari ulasan user. Sehingga penjual bisa memanfaatkannya untuk meningkatkan Customer Relationship Management (CRM) dengan melihat persepsi konsumen yang terbentuk karena memungkinkan bisnis mengikuti opini publik terkait dengan Image Produk SSD Patriot dan merespons terhadapat masalah user terkait persepsi yang negatif.

Hasil dari penelitian ini dapat digunakan oleh penjual untuk melihat ringkasan persepsi konsumen melalui ulasan user melalui produk SSD Patriot itu sendiri. Persepsi asosiasi yang muncul dapat dijadikan acuan dalam menentukan strategi penjual untuk mempertahankan citra Produk SSD Partriot yang sudah baik dan memperbaiki persepsi yang buruk untuk meningkatkan retensi pelanggan.

\section{SARAN}

Saran yang dapat diberikan oleh peneliti adalah agar PT Patriot Memory Indonesia selalu melakukan evaluasi terhadap produknya secara berkala dalam kegiatan penjualannya sehingga dapat mempertahankan citra produk SSD Patriot dan memperbaiki persepsi buruk dari pelanggan dengan cara memberikan layanan yang terbaik kepada konsumennya, serta memberikan layanan purna jual agar semakin mempererat hubungan dengan konsumennya. Selain itu diharapkan PT Patriot Memory Indonesia semakin meningkatkan strategi penjualan di beberapa $e$ commerce yang populer di Indonesia dan meningkatkan pemasarannya agar semakin dikenal oleh masyarakat luas. Pelayanan terhadap konsumen juga diperlukan terutama ketika konsumen mempunyai keluhan, pertanyaan mengenai 
produk Patriot SSD, dengan adanya perbaikan pelayanan akan semakin meningkatkan tingkat penjualan produknya.

\section{DAFTAR PUSTAKA}

Baum, David. 1999. E-commerce. PT Gramedia Pustaka Utama. Jakarta.

Dumbill. 2012. Big Data Now: 2012 Edition. O’Reilly Media Inc. USA.

Hurwitz. 2013. Big Data for Dummies. John Wiley \& Sons Inc. Hoboken. New Jersey.

Kalakota, R. and A. B. Whinston. 1997. Electronic Commerce: A Manager's Guide. Addison-Wesley: Reading. Mass. Harlow. England.

Kotler, Philip and Gary Armstrong. 2012. Principles of Marketing. Prentice Hall. New Jersey.

Laudon, J. and K. C. Laudon. 1998. Essential of Management Information System. Prentice Hall. New Jersey.

Liu. 2009. Social Computing and Behavioral Modeling. Phoenix Arizona. USA.

Moens. 2014. Mining User Generated Content. CRC Press. Boca Raton.

Provost. 2013. Data Science for Business. O’Reilly Media Inc. Gravenstein Highway North. Sebastopol.

Rinaldi, Made Kevin Bratawisnu, Muhammad Fulki Firdaus. 2018. Analisa Persepsi Customer Feedback E-commerce Tokopedia dan Bukalapak Menggunakan Text Network Analysis. Journal Information Engineering and Educational Technology, Vol 2, No. 1, pp. 6-12.

Turban, Efraim, Jon Outland, David King, Jae Kyu Lee, Ting-Peng Liang, and Deborrah C. Turban. 2018. Electronic Commerce 2018: A Managerial and Social Networks Perspective. Springer International Publishing AG.

Wong, Jony. 2010. Internet Marketing for Beginner. Elek Media Komputindo. Jakarta. 